\title{
Changes in cAMP-dependent protein kinase (PKA) and progesterone secretion in luteinizing human granulosa cells
}

\author{
E C Chin, T E Harris and D R E Abayasekara
}

Reproduction and Development Group, Department of Veterinary Basic Sciences, Royal Veterinary College, Royal College Street, London NW1 0TU, UK

(Requests for offprints should be addressed to E C Chin; Email: echin@rvc.ac.uk)

\begin{abstract}
Luteinization of follicular granulosa cells leads to an increase in progesterone secretion that is regulated by luteinizing hormone (LH). LH acts mainly by elevating intracellular cyclic $3^{\prime}, 5^{\prime}$-adenosine monophosphate (cAMP) and activating cAMP-dependent protein kinase (PKA). In this study, we have examined the role of PKA in relation to progesterone output by luteinizing human granulosa cells. Human granulosa cells were obtained by percoll gradient centrifugation of follicular aspirates of patients undergoing oocyte retrieval for assisted conception. Cells were cultured in serum-supplemented medium for up to 3 days in the presence and/or absence of human (h)LH and other cAMP-elevating agents. Spent medium was assayed for cAMP and progesterone content by specific RIA. Cell lysates were collected and assessed for PKA regulatory (R)II $\alpha$ /catalytic (C) $\alpha$ expression by Western blotting. Although basal progesterone secretion
\end{abstract}

increased progressively throughout culture, cAMP levels remained unchanged. Under basal conditions, PKA $\mathrm{RII} \alpha / \mathrm{C} \alpha$ expression appeared to increase throughout the 3-day culture period. In the presence of $\mathrm{hLH}$ and other cAMP-elevating agents, progesterone secretion increased in a dose-dependent manner coincident with an increase in cAMP. However, despite the increase in both progesterone secretion and cAMP accumulation, there was a dose-dependent decrease in both PKA RII $\alpha$ and C $\alpha$ expression. Thus, data presented in this study show that increases in progesterone secretion in luteinizing human granulosa cells can be dissociated from increases in PKA expression. This notion implies that progesterone secretion may be regulated by PKA-dependent as well as PKAindependent mechanisms.

Journal of Endocrinology (2004) 183, 39-50

\section{Introduction}

Following the surge in luteinizing hormone (LH) and ovulation, follicular remnants are transformed into the corpus luteum (CL) through the luteinization of granulosa and theca cells. This is an event essential to the establishment and maintenance of pregnancy (Spencer \& Bazer 2002). It is generally accepted that binding of LH to its G-protein-coupled receptor leads to the activation of the adenylate cyclase/cyclic-AMP (cAMP)/protein kinase A (PKA) signalling pathway (Marsh \& Savard 1966, Marsh 1970, Leung \& Steele 1992, Davis 1994). Thus, LH exerts its actions on progesterone synthesis primarily by elevating intracellular cAMP levels, leading to the activation of PKA, the activity of which has been shown to influence the expression (Strauss et al. 1999, Clark et al. 2001) or activity (Sugawara et al. 1995) of components of the steroidogenic pathway. Moreover, it has been shown that LH-induced gonadal steroidogenesis can also be regulated through cAMP/PKA-independent mechanisms (Cooke 1999, Wood \& Strauss 2002).
The diversity of PKA and its subunits has been extensively reviewed (Dosekland et al. 1993, Skalhegg \& Tasken 2000). In the absence of cAMP, the PKA holoenzyme exists as a tetramer composed of two regulatory (R) and two catalytic (C) subunits. When both binding sites on the $\mathrm{R}$ subunits are occupied by cAMP, the $\mathrm{R}$ subunits undergo a conformational change, which lowers their affinity for the $\mathrm{C}$ subunits. This results in the dissociation of the holoenzyme complex and renders the enzyme active (Skallhegg \& Tasken 2000). The catalytic subunits are then free to phosphorylate specific target proteins.

To date, four regulatory subunits have been identified (RI $\alpha$, RI $\beta$, RII $\alpha$ and RII $\beta$ ), which are differentially distributed in mammalian tissues (Skallhegg \& Tasken 2000). RI $\alpha$ and RII $\alpha$ are expressed ubiquitously, RI $\beta$ is expressed predominantly in the brain and RII $\beta$ is expressed primarily in brain, adrenal and adipose tissues (Edelman et al. 1987, Taylor et al. 1990). These R subunits define types I and II PKA, with both types of holoenzyme having three potential $\mathrm{C}$ subunits $(\alpha, \beta$ and $\gamma)$. The $\mathrm{C} \alpha$ and $\beta$ subunits share $93 \%$ homology and have broad tissue 
specificity, with $\mathrm{C} \alpha$ being the predominant species. The $\mathrm{C} \gamma$ subunit, however, has been readily identified only in the primate testis (Beebe et al. 1990).

Previous studies in the rat ovary have shown that RII is a major cytosolic phosphoprotein whose content and phosphorylation state are regulated by cAMP (Ratoosh \& Richards 1985). It has been shown In the porcine ovary that type I PKA is present in equivalent amounts in small follicles, large preovulatory follicles and CL. However, type II PKA is present in much greater amounts, with a moderate increase in RII expressed in preovulatory follicles relative to small follicles and CL (DeManno \& Hunzicker-Dunn 1991). Such reports suggest that type II, but not type I PKA, is hormonally regulated as a function of follicular differentiation in developing follicles. However, it has been reported that both types I and II PKA play a role in the regulation of steroidogenesis in other tissues (Whitehouse \& Abayasekara 1994).

There is further evidence to suggest that PKA may play a role in the process of luteinization. For example, in the primate ovary, luteinization is accompanied by dramatic changes in the responsiveness of luteal cells to LH and cAMP (Zeleznik 1998, Zeleznik \& Somers 1999). Moreover, in the rat ovary, it has been shown that inhibition of PKA inhibits morphological and physiological changes associated with luteinization (Morris \& Richards 1993, 1995). Therefore, in this study, we have investigated the changes in the cAMP/PKA system as human granulosa cells undergo luteinization and acquire the capacity to secrete large quantities of progesterone.

\section{Materials and Methods}

\section{Materials}

Human luteinizing hormone (hLH; NIDDK-hLH-BSIAFP-2 (6100 IU/mg)) was kindly donated by AF Parlow of the National Institute of Diabetes, Digestive and Kidney Diseases, National Hormone and Pituitary Program (Bethesda, MD, USA). Progesterone antibody was purchased from the Central Veterinary Laboratory (Reading, UK). $\left[{ }^{3} \mathrm{H}\right]$ Progesterone, $\left[{ }^{125} \mathrm{I}\right]$ cAMP-TME and Hyperfilm ECL were purchased from Amersham. cAMP standard and antibody were purchased from Calbiochem (Nottingham, UK). Protogel and SDS tank buffer were purchased from National Diagnostics (Hull, UK). Rabbit polyclonal anti-PKA $\mathrm{C} \alpha$ and rabbit polyclonal antiPKA RII $\alpha$ were purchased from Santa Cruz (Calne, UK). Monoclonal mouse antiglyceraldehyde-3-phosphate dehydrogenase (GAPDH) was purchased from Biogenesis Ltd (Poole, UK). Goat antirabbit IgG and bichinchoninic acid (BCA) reagent were purchased from Pierce (Chester, UK). Goat antimouse $\operatorname{IgG}$ was purchased from BD Transduction Laboratories (Cowley, UK). All other materials were purchased from Sigma (Poole, UK) or $\mathrm{BDH}$ (Poole, UK) at the equivalent of Analar grade.

\section{Patient samples}

Human granulosa cells were obtained from follicular aspirates of patients undergoing oocyte retrieval for assisted conception at Lister Hospital, London, UK, with informed patient consent (in accordance with the Declaration of Helsinki) and with approval of the local ethics committee. Pituitary downregulation was achieved by subcutaneous administration of a GnRH analogue (Suprecur; Shire Pharmaceuticals, Andover, UK; $500 \mu \mathrm{g} /$ day from day 2 of the cycle for 10-21 days). Administration of the GnRH analogue was then continued in conjunction with purified urinary human menopausal gonadotrophin (Menogon; Ferring Pharmaceuticals, Feltham, UK; 2-4 ampoules daily for 10-14 days) followed by a single injection of human chorionic gonadotrophin (Profasi; Serono, Welwyn Garden City, UK; 5000-10 000 IU) 36 h prior to oocyte collection in which follicles were aspirated under local anaesthesia via the transvaginal route.

\section{Isolation of human granulosa cells}

Human granulosa cells were isolated as previously described (Webley et al. 1988, Abayasekara et al. 1993a). Follicular aspirates from individual patients were centrifuged at $250 \mathrm{~g}$ for $10 \mathrm{~min}$ at $4{ }^{\circ} \mathrm{C}$. The supernatant was then aspirated, and cell pellets from individual patients were pooled and resuspended in phosphate-buffered saline (PBS), overlaid onto a 60\% (v/v) Percoll solution and centrifuged at $1000 \mathrm{~g}$ for $20 \mathrm{~min}$ at $4{ }^{\circ} \mathrm{C}$. Granulosa cells precipitated at the Percoll-PBS interface were aspirated, resuspended in PBS and centrifuged at $250 \mathrm{~g}$ at $4{ }^{\circ} \mathrm{C}$. This step was repeated three times. After the final wash, the supernatant was removed and the cell pellet was resuspended in PBS. Cell viability was determined by the trypan blue $(0.2 \% \mathrm{v} / \mathrm{v})$ dye exclusion method. The number of steroidogenic cells determined by $\Delta^{5}-3 \beta-$ hydroxysteroid dehydrogenase: $\Delta^{5-4}-$ isomerase (3ßHSD) cytochemistry (Aldred \& Cooke 1983) was routinely found to be in excess of $85 \%$.

\section{Culture of human granulosa cells}

Depending on experimental procedure, cells were plated in either 96-well plates or $35 \mathrm{~mm}$ culture dishes. For the measurement of progesterone and cAMP, cells were plated at a density of $2 \times 10^{4}$ cells per well/200 $\mu \mathrm{l}$ medium in 96-well plates. For immunological detection of PKA C $\alpha$ or PKA RII $\alpha$, cells were cultured in either individual $35 \mathrm{~mm}$ dishes or 6-well plates at a density of $10^{6}$ cells $/ 3 \mathrm{ml}$ medium. Granulosa cells were cultured for up to 3 days in Dulbecco's modified Eagle's medium nutrient mixture F12 (DMEM), supplemented with 10\% (v/v) fetal calf serum (FCS), $2 \mathrm{mM}$ glutamine and $1 \mathrm{IU} / \mathrm{ml}$ penicillinstreptomycin, and incubated at $37^{\circ} \mathrm{C}$ in a humidified atmosphere with $95 \% \mathrm{O}_{2}$ and $5 \% \mathrm{CO}_{2}$. 


\section{Progesterone RIA}

Progesterone content in the incubation medium was determined by an adaptation of the method previously described (Pallikaros et al. 1995). Prior to assay, samples were thawed, and diluted in assay buffer $(20 \mathrm{mM}$ $\mathrm{Na}_{2} \mathrm{HPO}_{4} \cdot 2 \mathrm{H}_{2} \mathrm{O}, 80 \mathrm{mM} \mathrm{Na} \mathrm{HPO}_{4} \cdot 12 \mathrm{H}_{2} \mathrm{O}, 150 \mathrm{mM}$ $\mathrm{NaCl}, 1 \%(\mathrm{w} / \mathrm{v}) \mathrm{NaN}_{3}, 0 \cdot 1 \%(\mathrm{w} / \mathrm{v})$ gelatine) such that they lay within the linear portion of the standard curve. The intra- and interassay coefficients of variation were $9 \cdot 4 \%$ and $10 \cdot 3 \%$ respectively.

\section{cAMP RIA}

Medium collected from cell cultures was acidified with $3 \mathrm{M}$ perchloric acid and stored at $-20^{\circ} \mathrm{C}$ to await analysis by RIA. Prior to assay, samples were thawed and neutralized by the addition of $2 \cdot 16 \mathrm{M} \mathrm{K}_{3} \mathrm{PO}_{4}$, to give a final concentration of $0 \cdot 154 \mathrm{M}$. cAMP concentrations were determined by specific radioimmunoassay by the method of Steiner et al. (1972), modified by the acetylation procedure of Harper and Brooker (1975), and validated for human granulosa cell-conditioned media by Abayasekara et al. (1993b). The intra- and interassay coefficients of variation were $10 \cdot 9 \%$ and $12 \cdot 4 \%$ respectively.

\section{Preparation of luteinizing human granulosa cell lysates}

After treatment of granulosa cells, cell lysates were prepared as previously described by Dewi et al. (2002). Incubation medium was aspirated from the dish, and the cells were rinsed with ice-cold PBS (pH 7·5). The wells of the culture dish were aspirated to dryness, and then lysis buffer (63.5 mM Tris-HCl (pH 6.8), 10\% (v/v) glycerol, $2 \%$ SDS, $1 \mathrm{mM}$ AEBSF [4-(2-aminoethyl) benzenesulfonyl fluoride] and $50 \mu \mathrm{g} / \mathrm{ml}$ leupeptin) was added to the cells, which were then left on ice for $10 \mathrm{~min}$. Next, the luteinizing granulosa cells were scraped from the culture dish into $1.5 \mathrm{ml}$ microfuge tubes. Cell lysates were then boiled at $100{ }^{\circ} \mathrm{C}$ for $5 \mathrm{~min}$. Protein content was determined by the BCA method, according to the manufacturer's instructions, and bromophenol blue and $\beta$-mercaptoethanol were added to the samples to give final concentrations of $0 \cdot 02 \%(\mathrm{w} / \mathrm{v})$ and $5 \%(\mathrm{v} / \mathrm{v})$ respectively. Samples were then stored at $-20{ }^{\circ} \mathrm{C}$ until required, when they were thawed, reboiled for $5 \mathrm{~min}$ at $100{ }^{\circ} \mathrm{C}$ and centrifuged at 13000 r.p.m. for $1 \mathrm{~min}$ before electrophoresis.

\section{SDS-PAGE and Western immunoblotting}

Whole granulosa-cell lysates proteins were separated by $10 \%$ SDS-PAGE (Wheeler-Jones et al. 1996). After electrophoresis, proteins were transferred to Immobilonpolyvinylidene difluoride (PVDF) membrane by the BioRad semidry blotting system. After transfer of proteins to a PVDF membrane, non-specific sites were blocked by a solution of Tris-buffered saline with Tween (TBS-T: $50 \mathrm{mM}$ Tris, $150 \mathrm{mM} \mathrm{NaCl}, 0 \cdot 02 \%$ (v/v) Tween-20, $\mathrm{pH} 7 \cdot 4)$, containing $10 \%(\mathrm{w} / \mathrm{v}) \mathrm{BSA}$, for $2 \mathrm{~h}$ at room temperature with gentle agitation. The membrane was then incubated with either anti-PKA $\mathrm{C} \alpha$ or anti-PKA RII $\alpha$ at a concentration of $0.4 \mu \mathrm{g} / \mathrm{ml}(1: 500)$ in TBS-T containing $10 \%(\mathrm{w} / \mathrm{v}) \mathrm{BSA}$ for at least $5 \mathrm{~h}$ at room temperature, or overnight at $4{ }^{\circ} \mathrm{C}$, with maximum speed of agitation. Next, the membrane was washed for $6 \times 10 \mathrm{~min}$ in TBS-T. Following the incubation of the membrane in a 1:10 000 dilution (in TBS-T plus $0 \cdot 2 \%(\mathrm{w} / \mathrm{v}) \mathrm{BSA}$ ) of horseradish peroxidase (HRP)-conjugated goat antirabbit $\operatorname{IgG}$ for $1 \mathrm{~h}$, the membrane was washed a further eight times for $10 \mathrm{~min}$ in TBS-T. Immunoreactive proteins were visualized by enhanced chemiluminescence (ECL).

To verify equal protein loading, blots were immersed in stripping buffer $(6 \cdot 25 \mathrm{mM}$ Tris- $\mathrm{HCl}, \mathrm{pH} 6 \cdot 7,2 \%(\mathrm{w} / \mathrm{v})$ SDS and $0.7 \%(\mathrm{v} / \mathrm{v}) \beta$-mercaptoethanol) and incubated for $30 \mathrm{~min}$ at $50{ }^{\circ} \mathrm{C}$. Stripped blots were then washed in TBS-T for $4 \times 10 \mathrm{~min}$, blocked and reprobed with antiGAPDH antibody and HRP-conjugated goat antimouse $\operatorname{IgG}$ for $1 \mathrm{~h}$ and visualized as previously described. Densitometric quantification of immunoreactive bands was carried out with a BioRad Model GS-690 Imaging Densitometer with BioRad Molecular Analyst software, Version 1·4.

\section{Statistical analysis}

For secretion studies, treatments were carried out in quadruplicate with cells from an individual patient. Each experiment was repeated on at least three occasions with cells from three individual patients. Data obtained from each individual patient were internally referenced with the relevant experimental control standardized to $100 \%$ before being pooled with data from three individual patients and expressed as mean \pm S.E.M. For immunoblotting studies, immunoblots shown are representative of experiments carried out with cells from three individual patients. Data obtained from densitometric measurements of the bands from three separate experiments have been pooled and are expressed as mean \pm S.E.M. Statistical analysis was carried out on non-referenced data by one-way ANOVA with repeated measures, followed by Dunnet's multiple comparison test or unpaired $t$-test as appropriate, using the Graph Pad Prism software package (San Diego, CA, USA). Probabilities of less than or equal to $0 \cdot 05$ were accepted as significant.

\section{Results}

Basal progesterone secretion, cAMP accumulation and PKA $C a$ and RIIa expression during luteinization of human granulosa cells

Granulosa cells were cultured for 0-24 h (day 1), 24-48 h (day 2) and $48-72 \mathrm{~h}$ (day 3) in the absence of any 
treatment. Basal progesterone secretion by cultured granulosa cells increased progressively over 3 days in culture with a significant increase being observed on day 3 of culture (Fig. 1A). During this transformation of granulosa cells to granulosa-lutein cells, basal cAMP levels remained unchanged (Fig. 1B). The expression of both PKA Ca (Fig. 1C) and RIIa (Fig. 1D) appeared to increase during culture when compared with expression on day 1; however, this increase was not statistically significant. Blots were stripped and probed with anti-GAPDH antibody to verify even protein loading (Fig. 1C).

Effect of hLH and forskolin and dibutyryl cAMP (dbcAMP) on progesterone production during luteinization

LH interaction with its G-protein-coupled receptor leads to the activation of the adenylate cyclase-cAMP-PKA signalling system. Luteinizing granulosa cells were treated with up to $1000 \mathrm{ng} / \mathrm{ml} \mathrm{hLH}$ on days 1 and 3 of culture for $24 \mathrm{~h}$. As expected, concentration-dependent stimulation of progesterone secretion was observed on each day of culture. The sensitivity of the cells to stimulation increased during luteinization; that is, on day 1 of culture $100 \mathrm{ng} / \mathrm{ml}$ $\mathrm{hLH}$ was the minimum dose required to elicit a significant increase in progesterone production (Fig. 2A), whereas $10 \mathrm{ng} / \mathrm{ml} \mathrm{hLH}$ was the minimum dose required to elicit significant responses on day 3 of culture. Similar changes in sensitivity were obtained with a range of concentrations of the adenylate cyclase activator, forskolin (Fig. 2B), or the cell-permeable cAMP analogue, dbcAMP (Fig. 2C).

\section{Effect of hLH and forskolin on CAMP accumulation during luteinization}

For detailed dose-response studies, luteinizing granulosa cells were exposed to either hLH $(0 \cdot 1-1000 \mathrm{ng} / \mathrm{ml})$ (Fig. 3A) or forskolin $(0 \cdot 001-10 \mu \mathrm{M})$ (Fig. 3B) for $8 \mathrm{~h}$ on days 1 and 3 of culture. In addition, time-course studies were carried out for up to $8 \mathrm{~h}$, using either $100 \mathrm{ng} / \mathrm{ml}$ hLH or $10 \mu \mathrm{M}$ forskolin (Fig. 4A-C). It is evident from the data presented in Fig. 3 that both hLH and forskolin were able to elicit dose-dependent increases in cAMP accumulation on each day of culture. Time-course studies revealed that on day $1, \mathrm{hLH}$ had virtually no effect on cAMP accumulation relative to control (Fig. 4A). However, significant increases in cAMP production (relative to time-matched untreated control) were seen after 2-h incubation on day 2 (Fig. 4B) and after 10-min incubation on day 3 (Fig. 4C). Forskolin was able to elicit significant increases in cAMP production after 10-min incubation on day 1 and 5-min incubation on days 2 and 3 of culture, an effect that was maintained for up to $8 \mathrm{~h}$. On day 3 of culture, there were no significant differences between $\mathrm{hLH}$ and forskolin in their relative abilities to stimulate cAMP accumulation.
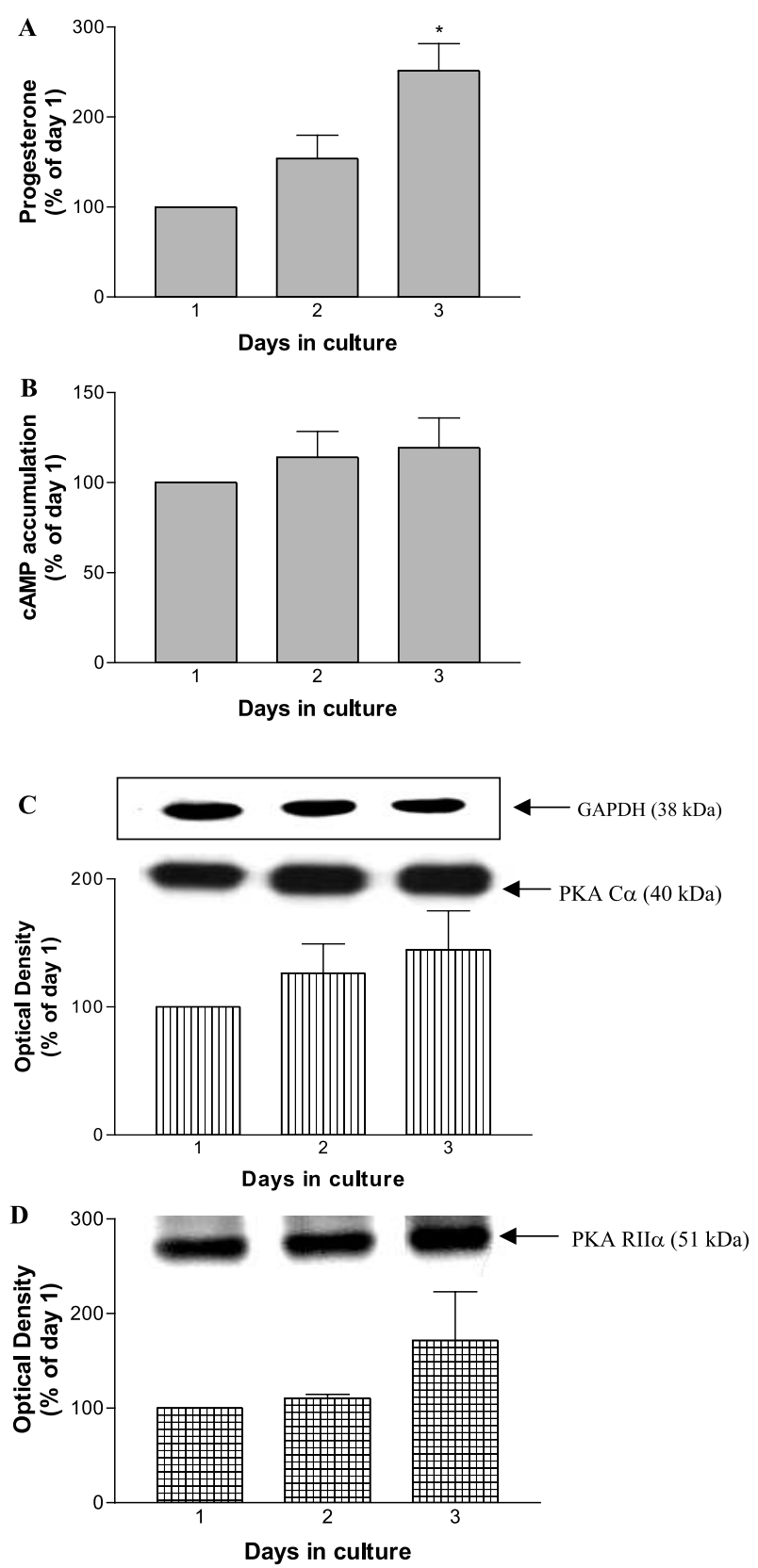

Figure 1 Basal progesterone production, cAMP levels and PKA $(\mathrm{C} \alpha / \mathrm{RIl} \alpha)$ expression by luteinizing human granulosa cells. Granulosa cells were cultured for 24-h periods for up to 3 days, and spent media was analysed for (A) progesterone secretion, (B) cAMP levels, (C) GAPDH/C $\alpha$ expression and (D) Rll $\alpha$ expression. Data are expressed as mean \pm S.E.M. $(n=3) .{ }^{*} P<0 \cdot 05$ relative to day 1 of culture. Blots show data from a single experiment. Optical density data shown are cumulative and obtained from three experiments carried out with cells from three individual patients. Basal progesterone secretion on day 1 was $1.66 \pm 0.5 \mathrm{nmol}$ per $10^{5}$ cells $/ 24 \mathrm{~h}$. Basal cAMP accumulation on day 1 was $22 \cdot 3 \pm 4 \cdot 3 \mathrm{pmol} / 10^{5}$ cells. Optical density values for GAPDH expression are expressed as mean percentage of day $1 \pm$ S.E.M.: day $2,96 \cdot 8 \pm 7 \cdot 0$; day $3,104 \cdot 1 \pm 2 \cdot 1 . n=3$. 


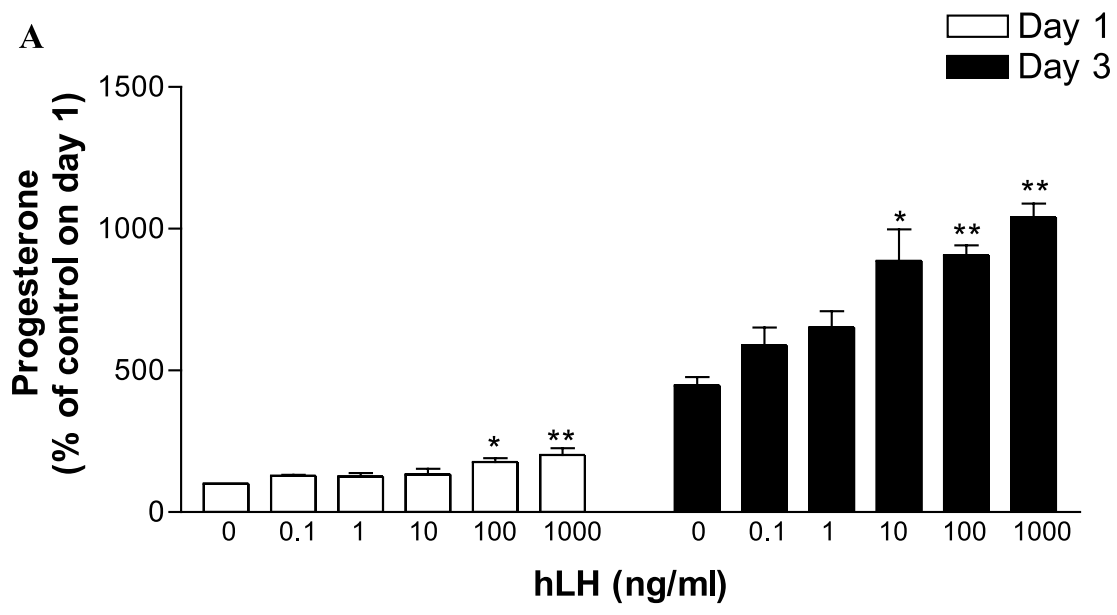

B
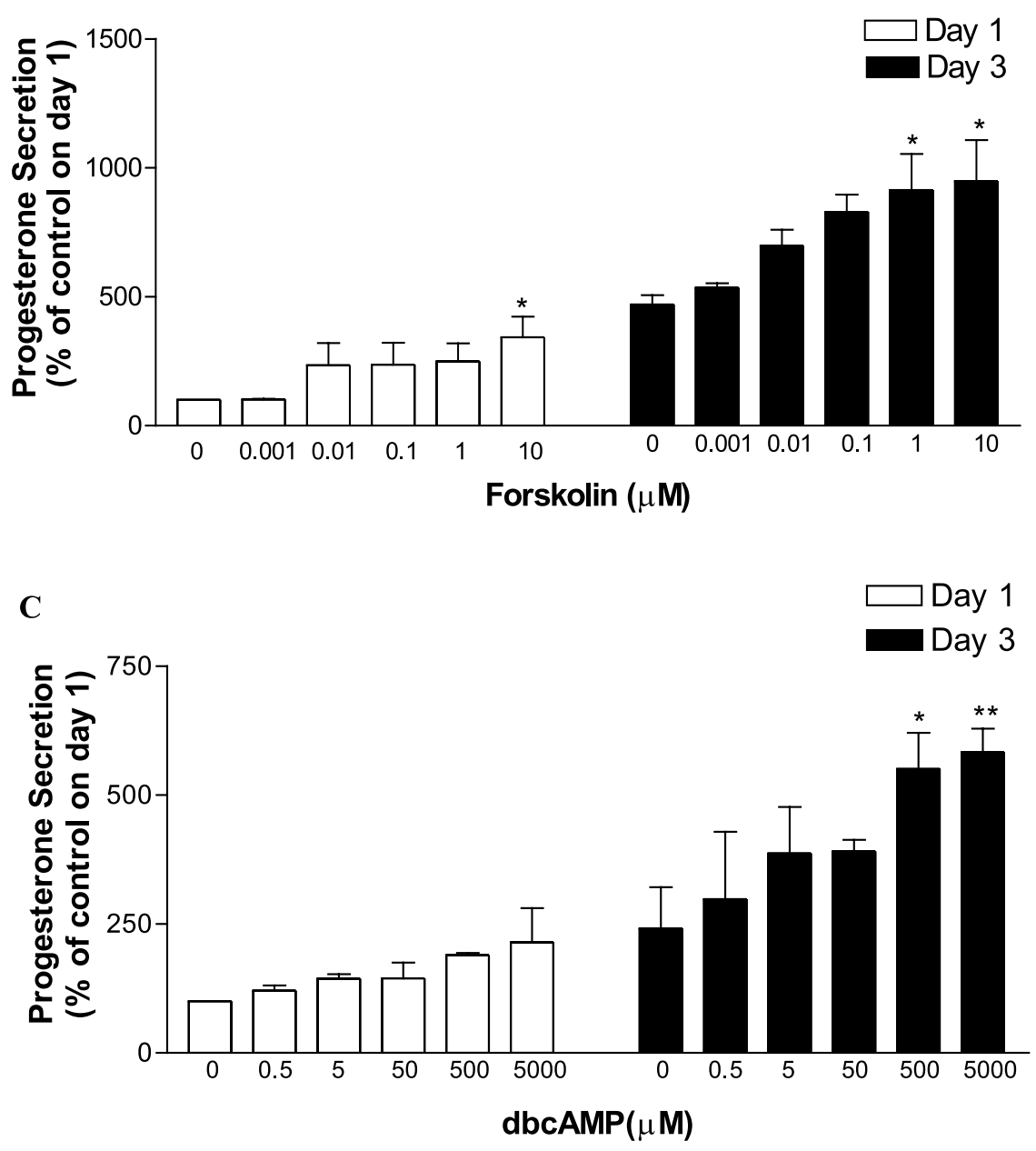

Figure 2 Effects of $\mathrm{hLH}$, forskolin and dbcAMP on progesterone production. Granulosa cells were cultured for 24-h periods for up to 3 days, and on days 1 and 3, cells were treated with (A) hLH $(0 \cdot 1-1000 \mathrm{ng} / \mathrm{ml})$, (B) forskolin $(0 \cdot 001-10 \mu \mathrm{M})$ or $(\mathrm{C}) \mathrm{dbcAMP}$

$(0 \cdot 5-5000 \mu \mathrm{M})$. Spent medium was analysed for progesterone content. Data are expressed as mean \pm S.E.M. $n=3$ experiments, using cells from three individual patients. ${ }^{*} P<0 \cdot 05 ;{ }^{*} P<0 \cdot 01$ relative to control on the corresponding day of culture. Basal progesterone secretion on day 1 was $1 \cdot 22 \pm 0 \cdot 7 \mathrm{nmol}$ per $10^{5}$ cells $/ 24 \mathrm{~h}$. 
A
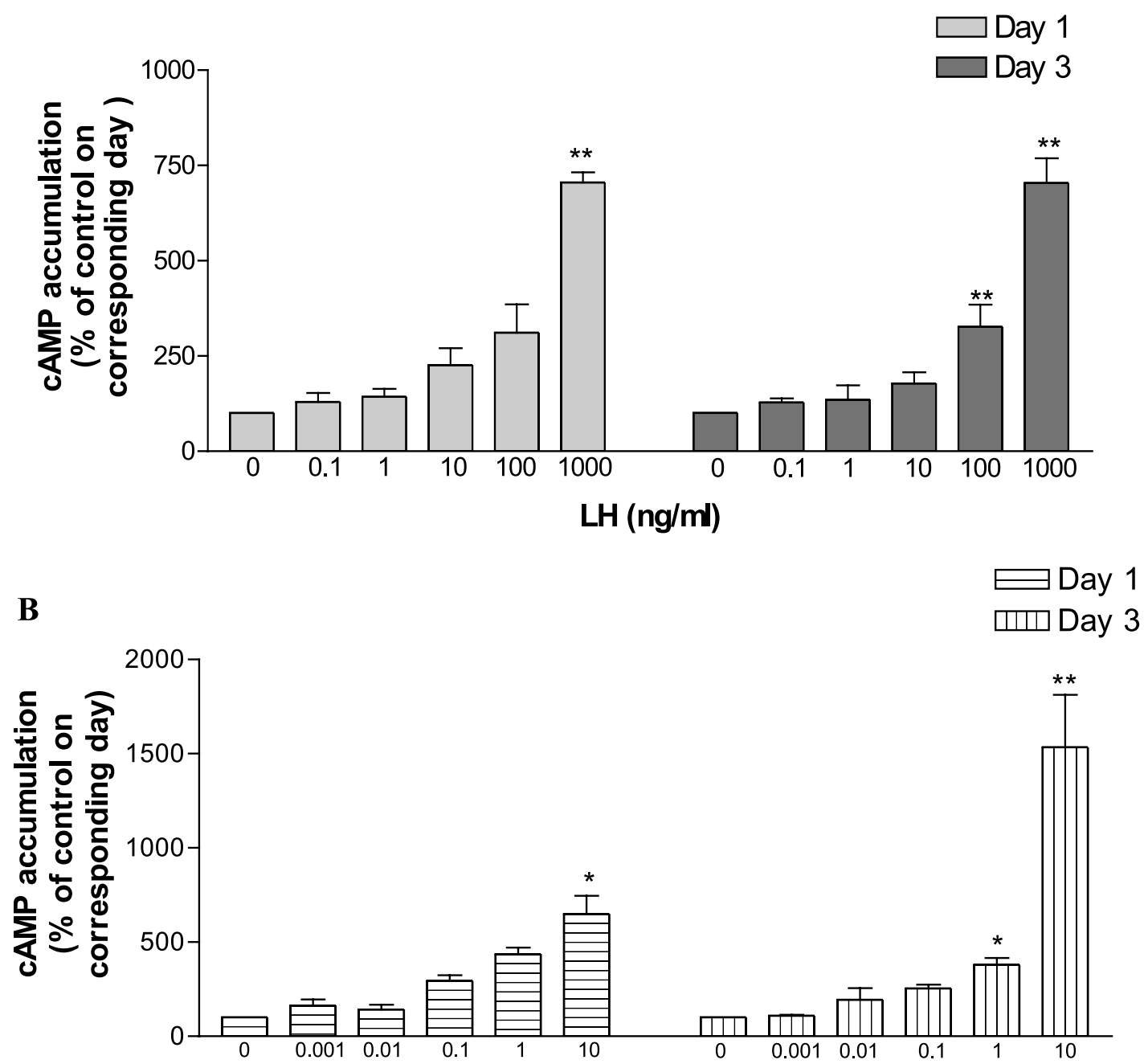

Forskolin $(\mu \mathbf{M})$

Figure 3 Effects of hLH and forskolin on cAMP generation. Granulosa cells were cultured for up to 3 days; on days 1 and 3 of culture, cells were incubated with either (A) hLH $(0 \cdot 1-1000 \mathrm{ng} / \mathrm{ml})$ or (B) forskolin $(0 \cdot 001-10 \mu \mathrm{M})$ for $8 \mathrm{~h}$. Spent medium was analysed for CAMP content. Data are expressed as mean \pm S.E.M. $n=3$ experiments using cells from three individual patients. ${ }^{*} P<0 \cdot 05 ;{ }^{*} P<0 \cdot 01$ relative to control on the corresponding day of culture. Basal cAMP accumulation (A) day 1: $35 \cdot 2 \pm 1 \cdot 4$; day $3: 32 \cdot 1 \pm 3 \cdot 1$ (B) day 1: $29 \cdot 1 \pm 2 \cdot 3$; day 3 : $33 \cdot 7 \pm 1 \cdot 1 \mathrm{pmol} / 10^{5}$ cells.

Effect of $h L H$ and forskolin on PKA C $\alpha$ and RII $\alpha$ expression during luteinization

Given that gonadotrophins and other cAMP elevating agents were able to elicit concentration-dependent increases in progesterone synthesis during luteinization, we examined the effect of these agents on PKA C $\alpha /$ RII $\alpha$ expression during luteinization. Surprisingly, exposure of cells to both hLH and forskolin markedly reduced both
PKA C $\alpha$ and RII $\alpha$ subunit expression in a concentrationdependent manner on days 1 and 3 of culture. Thus, granulosa cells cultured in the presence of increasing doses of either hLH (Fig. 5A and B) or forskolin (Fig. 6A and B) expressed significantly less PKA C $\alpha /$ RII $\alpha$ during each period of culture. Similar inhibitory responses were obtained with maximal doses of other physiological and pharmacological modulators of cAMP ( $\mathrm{PGE}_{2}$, dbcAMP and cholera toxin - data not shown). 


\section{Discussion}

Following the LH surge and ovulation of an oocyte, the remaining granulosa and theca cells of the collapsed follicle undergo transition to luteal cells to form the corpus

$\mathbf{A}$

Day 1

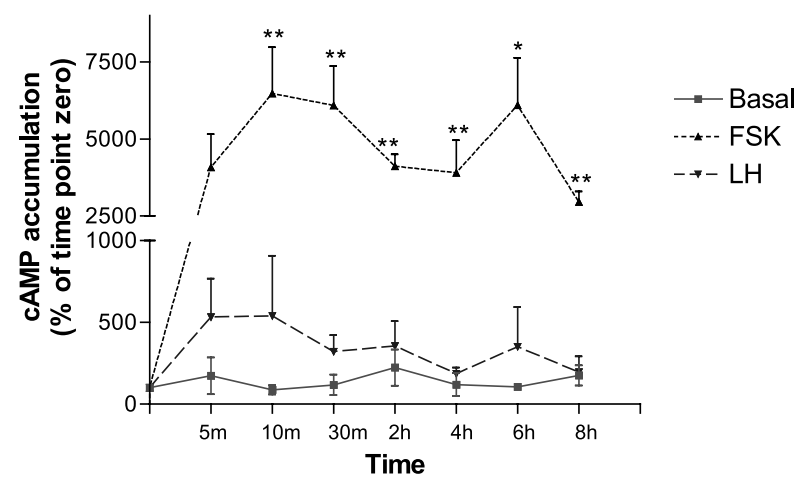

B

Day 2

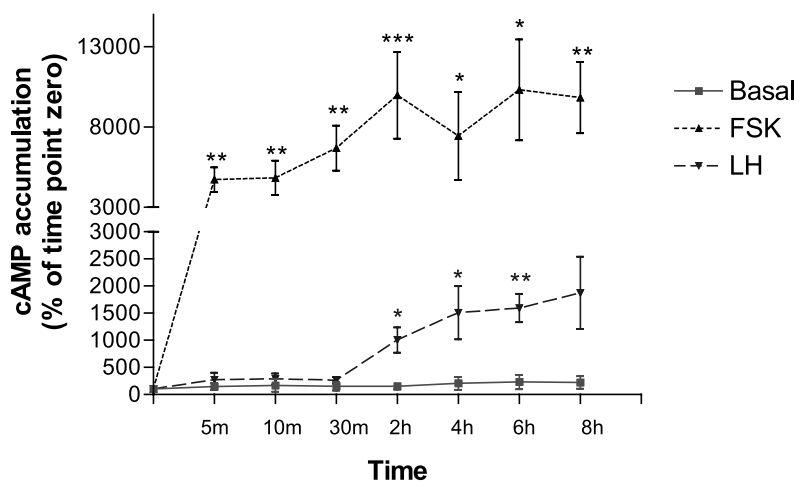

C Day 3

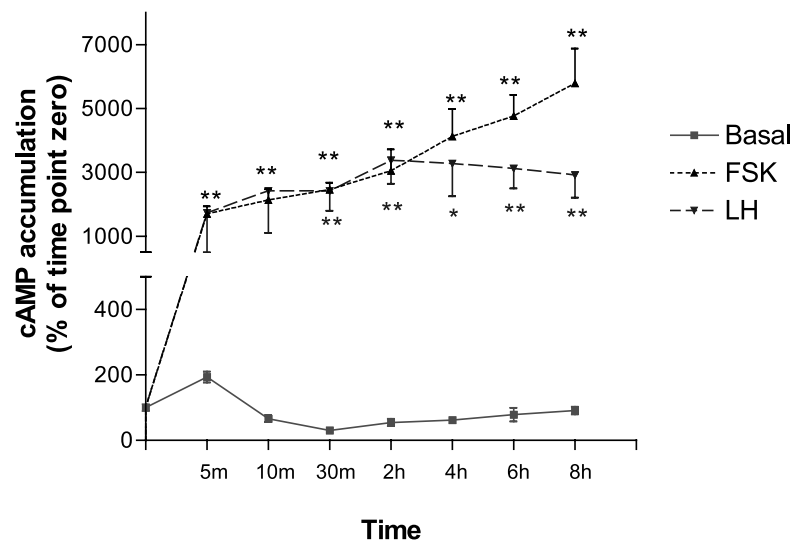

luteum. In this study, granulosa cells cultured under basal conditions increased progesterone output as the cells became more luteinized. These observations are consistent with previous reports of granulosa cell luteinization (Wickings et al. 1986, Fisch et al. 1989, Fowkes et al. 2001). Interestingly, our present study shows that, as granulosa cells luteinized, their responsiveness to $\mathrm{LH}$ and other cAMP-elevating agents was changed in terms of progesterone secretion. Thus, on day 3 of culture, hLH was able to elicit a greater increase in progesterone secretion than that induced on day 1 of culture. Similar changes in responsiveness were noted with both forskolin and dbcAMP.

Changes in progesterone secretion induced by $\mathrm{hLH}$ and forskolin were accompanied by dose- and time-dependent increases in cAMP generation. However, despite the enhanced responsiveness of human granulosa cells to these agents, basal cAMP levels remained unchanged throughout culture. This stimulation of progesterone secretion by $\mathrm{hLH}$ is thought to be due to an increase in cAMP generation rather than an inhibition of phosphodiesterase activity (Marsh 1970), and it is known that increases in cAMP enhance steroidogenesis by increasing specific mRNAs, which encode components of the steroidogenic pathway, such as $3 \beta-H S D$ and Cytochrome P450 sidechain cleavage (Strauss et al. 1988).

The data presented here show that cAMP generation in luteinizing human granulosa cells was also found to be time-dependent. Notably, on day 1, hLH (100 ng/ml) could not significantly stimulate cAMP generation. This concentration of hLH $(100 \mathrm{ng} / \mathrm{ml})$ is supraphysiological. However, due to the nature of the cells (ovarian hyperstimulation) and the experimental design of this study (stimulation on day 1 of culture), the concentrations of $\mathrm{LH}$ used were effective throughout the culture period. Moreover, previous studies have used similar or greater doses of $\mathrm{LH} / \mathrm{hCG}$ as an effective concentration to investigate progesterone secretion in this cell type (Polan et al.1986, Khan-Dawood et al.1989, Lee et al.1997).

Exposure to an ovulatory dose of hCG can lead to a loss of response through a combination of receptor downregulation (that is, a loss of receptor numbers) and desensitization, whereby the receptor becomes phosphorylated, resulting in its uncoupling from the Gs protein, and internalization (Ascoli et al. 2002). Thus, receptor

Figure 4 Time-dependent effects of hLH and forskolin on cAMP generation by luteinizing granulosa cells. Granulosa cells were incubated for up to $8 \mathrm{~h}$ in the presence or absence of either hLH (100 ng/ml) or forskolin $(10 \mu \mathrm{M})$ on (A) day 1 , (B) day 2 and (C) day 3 of culture. Spent medium was analysed for CAMP content. Results are expressed as mean \pm S.E.M. $n=3$ experiments using cells from three individual patients. ${ }^{*} P<0 \cdot 05 ;{ }^{* *} P<0 \cdot 01$; ${ }^{* * *} P<0 \cdot 001$ relative to control at the corresponding time point. Basal cAMP values at time zero were $49 \cdot 5 \pm 2 \cdot 4$ on day 1 , $45 \cdot 3 \pm 8 \cdot 4$ on day 2 and $55 \cdot 3 \pm 18 \cdot 9$ on day 3 pmol $/ 10^{5}$ cells. 


\section{$\mathrm{C} \alpha$}

\section{A}
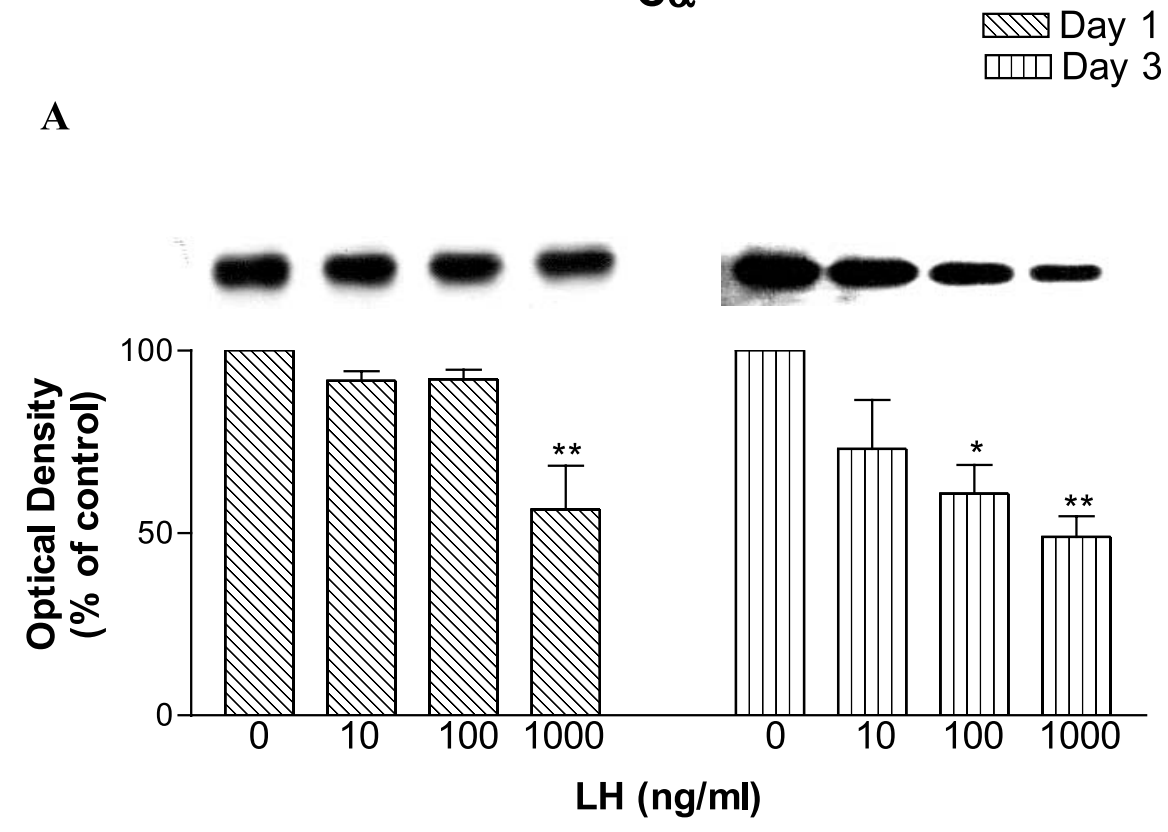

B

RIl $\alpha$
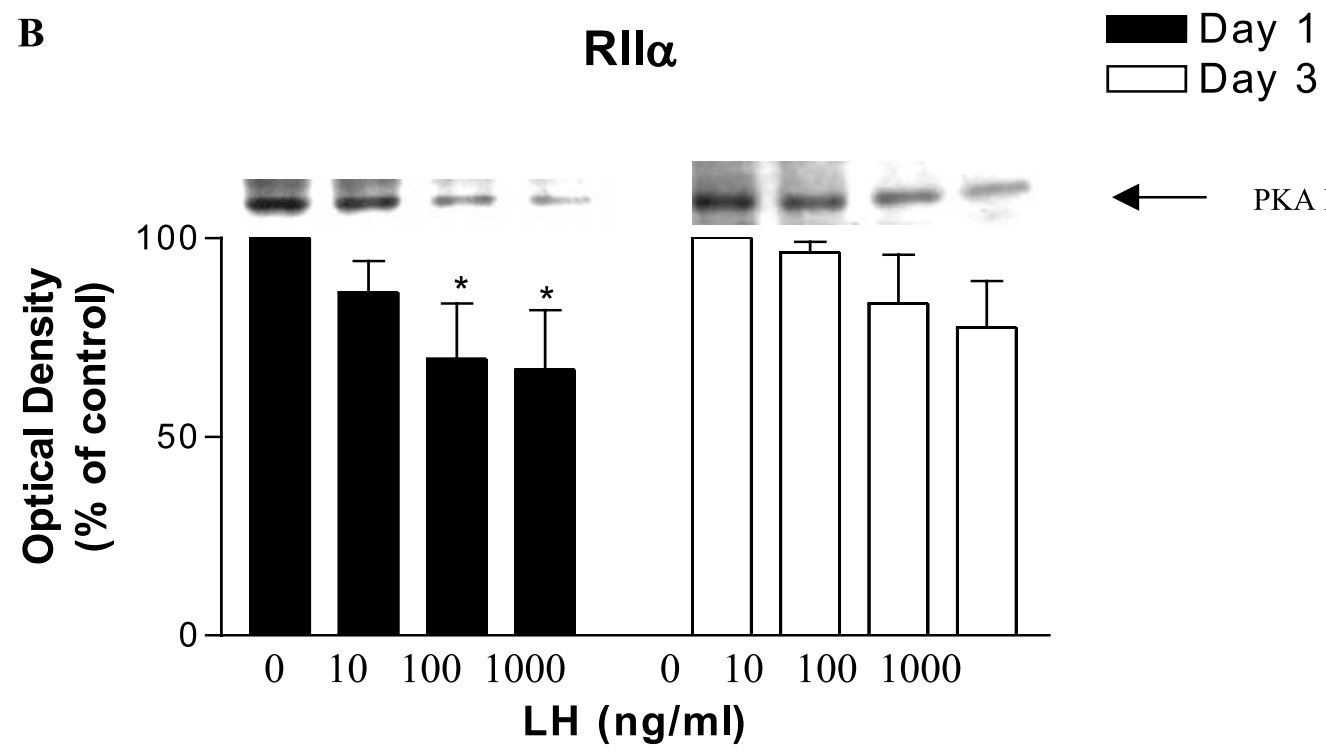

Figure 5 Dose-dependent effects of hLH on PKA $(\mathrm{C} \alpha / \mathrm{Rll} \alpha)$ expression by luteinizing human granulosa cells. Luteinizing human granulosa cells were incubated in the presence or absence of increasing doses of hLH $(10-1000 \mathrm{ng} / \mathrm{ml})$ on days 1 and 3 of culture. After each 24-h incubation period, cells were lysed and $25 \mu \mathrm{g}$ protein were separated by SDS-PAGE, transferred to a PVDF membrane and probed with an antibody that recognized either the (A) C $\alpha$ or (B) RIl $\alpha$ subunit of PKA. Blots shown represent data from a single experiment. Optical density data shown are cumulative and were obtained from three experiments carried out with cells from three individual patients. ${ }^{*} P<0 \cdot 05 ;{ }^{*} P<0 \cdot 01$ relative to corresponding control. 
A

$C \alpha$ MV Day 1

Day 3

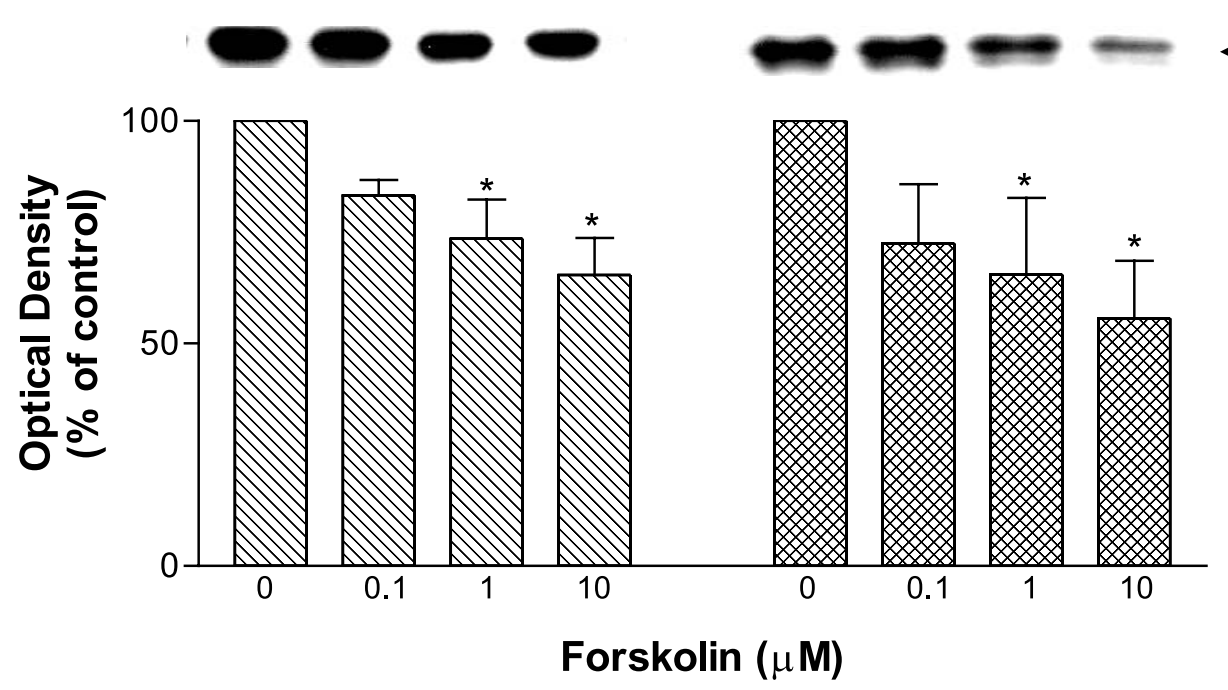

B

RIla

$\rightleftarrows$ Day 1

미 Day 3

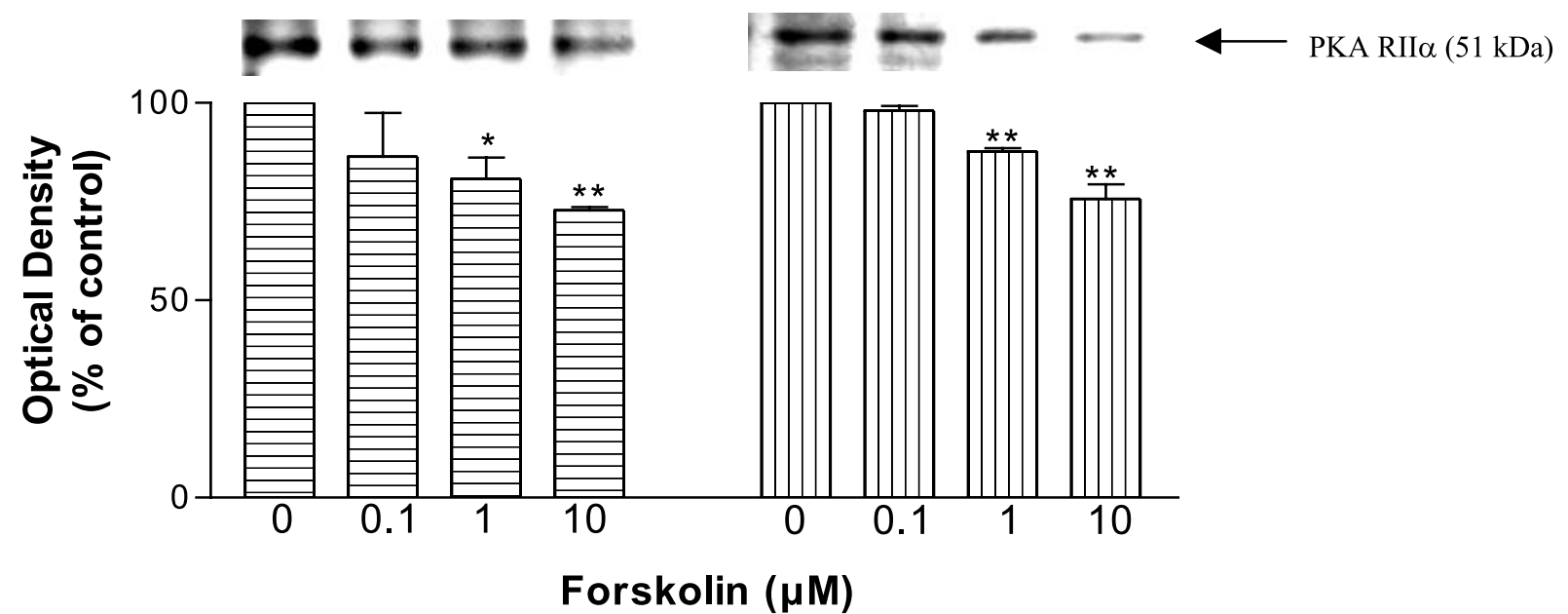

Figure 6 Dose-dependent effects of forskolin on PKA $(\mathrm{C} \alpha / \mathrm{RIl} \alpha)$ expression by luteinizing human granulosa cells. Luteinizing human granulosa cells were incubated in the presence or absence of increasing does of forskolin $(0 \cdot 1-10 \mu \mathrm{M})$ on days 1 and 3 of culture. After each 24-h incubation period, cells were lysed, and $25 \mu \mathrm{g}$ protein were separated by SDS-PAGE, transferred to a PVDF membrane and probed with an antibody that recognized either the (A) C $\alpha$ or (B) Rll $\alpha$ subunit of PKA. Blots shown represent data from a single experiment. Optical density data shown are cumulative and obtained from three experiments carried out with cells from three individual patients. ${ }^{*} P<0 \cdot 05 ;{ }^{* *} P<0 \cdot 01$ relative to corresponding control. 
desensitization ultimately leads to a loss of any further signal (Leung \& Steele 1992, Amsterdam et al. 2002). Receptor downregulation is a known mechanism by which target cells can reduce their response to an agonist through prolonged exposure (Amsterdam et al. 2002, Ascoli et al. 2002). Hence, a further challenge with LH, which utilizes the same receptor as hCG, would have little or no effect on progesterone secretion. In rat ovaries, for example, it has been shown that the preovulatory LH surge causes marked downregulation of the cell-surface LH receptor, which recovers upon luteinization (Segaloff et al. 1990, Peegel et al. 1994). The study by Peegel et al. (1994) lends support to our present data in terms of receptor downregulation with respect to cAMP generation, as, on day 1 of culture, $100 \mathrm{ng} / \mathrm{ml} \mathrm{hLH}$ were unable to stimulate cAMP generation, whereas, on day 3 of culture, hLH significantly increased cAMP generation compared with the control. However, forskolin was able to elicit increases in cAMP generation after $10 \mathrm{~min}$ on each day of culture. This response could be explained by the fact that forskolin acts in a receptor-independent manner by stimulating adenylate cyclase in order to raise intracellular cAMP (Jammes et al. 1988, Asboth et al. 2001).

Here we present data to show that chronic elevation of cAMP, whether by physiological (e.g. hLH) or pharmacological (e.g. dbcAMP and forskolin) means, leads to an increase in progesterone production coincident with a decrease in both the $\mathrm{C} \alpha$ and regulatory RII $\alpha$ subunits of PKA, during luteinization of human granulosa cells. As progesterone output increases despite an apparent decrease in $\mathrm{C} \alpha$ expression, it is possible that this decrease is due to the raised steroidal output. However, similar findings were reported in non-steroidogenic tissue where prolonged exposure of rat hepatocytes to glucagon was found to lead to prolonged, enhanced cAMP levels, which were associated with a decease in $\mathrm{C} \alpha$ expression that could not be accounted for by changes in C $\alpha$ mRNA expression (Houge et al. 1990). Similar results have also been reported in rat pituitary GH3 cells (Richardson et al. 1990) and in mutant lymphocytes (Steinberg \& Agard 1981), where the apparent decrease in the expression of $\mathrm{C} \alpha / \mathrm{RII} \alpha$ subunit was suggested to have been due to an enhanced rate of degradation. Hence, increased degradation of C $\alpha /$ RII $\alpha$ subunits in response to prolonged exposure to cAMP provides the most likely explanation for the decreases in PKA subunit expression observed in the present study.

It has been generally accepted that $\mathrm{LH}$ activates its G-protein-coupled receptor in the ovary, leading to the activation of adenylate cyclase, and resulting in an increase in intracellular cAMP, and thus an increase in the activity of PKA, that ultimately increases progesterone secretion. However, the apparent decreases in the expression of PKA subunits induced by $\mathrm{LH}$ (and other agents that raise intracellular cAMP levels), as demonstrated in this study, suggest that the ability of luteinizing granulosa cells to secrete progesterone can be dissociated from increases in
PKA C $\alpha$ and RII $\alpha$ expression; that is, steroid synthesis becomes less dependent on PKA C $\alpha$ and RII $\alpha$ expression as luteinization proceeds. While changes in PKA activity were not determined in this study, the presumption is that the decrease in expression of the PKA subunits $(\mathrm{C} \alpha$ and RII $\alpha$ ) did indeed lead to reduction in PKA activity.

These results thus suggest that an increase in PKA C $\alpha$ and RII $\alpha$ expression/activity may not be the sole means by which progesterone secretion is regulated during luteinization. In man, the functional lifespan of the CL is approximately 14-16 days, during which time progesterone secretion is maintained under the influence of LH (Hutchinson \& Zeleznik 1984, Hall 1993). Therefore, extrapolation of our current findings that $\mathrm{LH}$ treatment in vitro caused a profound inhibition $(42 \cdot 6 \pm 4 \cdot 8 \%)$ of $\mathrm{C} \alpha$ expression suggests that during luteinization and CL development in vivo, PKA expression/activity should decrease. This is consistent with the reported inhibitory effects of treatment in vivo with hCG on PKA activity in the macaque CL (Benyo \& Zeleznik 1997). Hence, despite the decrease in expression of both the RII $\alpha$ and $\mathrm{C} \alpha$ subunits of PKA, the cells continue to secrete large amounts of progesterone. This notion implies that other signalling pathways may be involved in the regulation of progesterone secretion by luteinizing granulosa cells.

The discovery of a new class of cAMP-binding proteins, the cAMP-guanine nucleotide exchange factors (cAMPGEFs) (de Rooij et al. 1998), has yielded an alternative intracellular target to PKA that could be activated by cAMP. Although transcripts for both cAMP-GEFI and cAMP-GEFII have been identified in the rat ovary (Gonzalez-Robayna et al. 2000), expression has not yet been identified at the protein level in the human ovary. Thus, in the accompanying paper, we provide evidence to support the notion that cAMP-GEFI signalling contributes to the regulation of progesterone secretion during luteinization.

\section{Acknowledgements}

We are grateful to the patients and staff at Lister Hospital for the provision of follicular aspirates. This work was supported by the BBSRC $(99 / \mathrm{B} 1 / \mathrm{S} / 05251)$ and the Welcome Trust (056630/Z/99/JMW/NP/JF).

\section{References}

Abayasekara DRE, Jones PM, Persaud SJ, Michael AE \& Flint APF 1993a Prostaglandin $F_{2 \alpha}$ activates protein kinase $C$ in human ovarian cells. Molecular and Cellular Endocrinology 91 51-57.

Abayasekara DRE, Michael AE, Webley GE \& Flint APF $1993 b$ Mode of action of prostaglandin $\mathrm{F}_{2 \alpha}$ in human luteinized granulosa cells: role of protein kinase C. Molecular and Cellular Endocrinology 97 81-91.

Aldred LF \& Cooke B 1983 The effect of cell damage on the density and steroidogenic capacity of rat testis Leydig cells, using an NADH exclusion test for determination of viability. Journal of Steroid Biochemistry 18 411-414. 
Amsterdam A, Hanoch T, Dantes A, Tajima K, Strauss JF 3rd \& Serger R 2002 Mechanisms of gonadotrophin desensitisation. Molecular and Cellular Endocrinology 187 69-74.

Asboth G, Price SA, Bellinger J, Ledger W, Barlow DH \& Bernal AL 2001 Characterization of adenylyl cyclases in cultured human granulosa cells. Reproduction 121 217-228.

Ascoli M, Fanelli F \& Segaloff DL 2002 The

lutrophin/choriogonadotrophin receptor, a 2002 perspective. Endocrine Reviews 23 141-174.

Beebe SJ, Oyen O, Sandburg M, Hansson V \& Jahnsen T 1990 Molecular cloning of a tissue specific protein kinase (C gamma) from human testis - representing a third isoform of the catalytic subunit of cAMP-dependent protein kinase. Molecular Endocrinology 4 465-475.

Benyo DF \& Zeleznik AJ 1997 Cyclic adenosine monophosphate signalling in the primate corpus luteum: maintenance of protein kinase A activity throughout the luteal phase of the menstrual cycle. Endocrinology 138 3452-3458.

Clark BJ, Ranganathan V \& Combs R 2001 Steroidogenic acute regulatory protein expression is dependent upon post-translational effects of cAMP-dependent protein kinase A. Molecular and Cellular Endocrinology 28 183-192.

Conti M 2002 Specificity of the cyclic adenosine $3^{\prime}, 5^{\prime}$-monophosphate signal in granulosa cell function. Biology of Reproduction $\mathbf{6 7}$ 1653-1661

Cooke BA 1999 Signal transduction involving cyclic AMP-dependent and cyclic AMP-independent mechanisms in the control of steroidogenesis. Molecular and Cellular Endocrinology 151 25-35.

Davis JD 1994 Mechanisms of hormone action: luteinizing hormone receptors and second-messenger pathways. Current Opinion in Obstetrics and Gynecology 6 254-261.

DeManno DA \& Hunzicker-Dunn M 1991 cAMP-dependent protein kinase isozymes in porcine follicles and corpora lutea. Molecular and Cellular Endocrinology 80 91-104.

Dewi DA, Abayasekara DRE \& Wheeler-Jones CPD 2002 Requirement for ERK1/2 activation in the regulation of progesterone production in human granulosa-lutein cells is stimulus specific. Endocrinology 143 877-888.

Doskeland SO, Maronde E \& Gjertsen BT 1993 The genetic subtypes of cAMP-dependent protein kinase - functionally different or redundant? Biochimica et Biophysica Acta 1178 243-258.

Edelman AM, Blumenthal DK \& Krebs EG 1987 Protein serine/threonine kinases. Annual Review of Biochemistry 56 567-561.

Fisch B, Margara RA, Winston RM \& Hillier SG 1989 Cellular basis of luteal steroidogenesis in the human ovary. Journal of Endocrinology 122 303-311.

Fowkes RC, Chandras C, Chin EC, Okolo S, Abayasekara DRE \& Michael AE 2001 Relationship between the production of prostaglandins and progesterone by luteinizing human granulosa cells. Journal of Endocrinology 171 455-462.

Gonzalez-Robayna IJ, Falender AE, Ochsner S, Firestone GL \& Richard JS 2000 Follicle-stimulating hormone (FSH) stimulates phosphorylation and activation of protein kinase $\mathrm{B}$ (PKB/Akt) and serum and glucocorticoid-induced kinase (Sgk): evidence for A kinase-independent signalling by FSH in granulosa cells. Molecular Endocrinology 14 1283-1300.

Hall JE 1993 Gonadotropin-releasing hormone antagonists: effects on the ovarian follicle and corpus luteum. Clinical Obstetrics and Gynecology 36 744-752.

Harper JF \& Brooker G 1975 Femtomole sensitive radioimmunoassay for cyclic AMP and cyclic GMP after 2'0 acetylation by acetic anhydride in aqueous solution. Journal of Cyclic Nucleotide Research $\mathbf{1}$ 207-218.

Houge G, Karsten O, Vintermyr K \& Doskeland SO 1990 The expression of cAMP-dependent protein kinase subunits in primary rat hepatocyte cultures. Cyclic AMP down-regulates its own effector system by decreasing the mRNAs for the inhibitory (R) subunits of cAMP-dependent protein kinase. Molecular Endocrinology 4 481-488.

Hutchinson JS \& Zeleznik AJ 1984 The rhesus monkey corpus luteum is dependent on pituitary gonadotropin secretion throughout the luteal phase of the menstrual cycle. Endocrinology 115 1780-1786.

Jammes H, de la Llosa-Hermier MP, Martinet J \& Hermier C 1988 Concurrent $\mathrm{LH}$ and forskolin action on adenylate cyclase activation and progesterone synthesis in corpora lutea from pregnant ewes. Endocrine Research 14 177-201.

Lee A, Christenson LK, Patton PE, Burry KA \& Stouffer RL 1997 Vascular endothelial growth factor production by human luteinized granulosa cells in vitro. Human Reproduction 12 2756-2761.

Leung PC \& Steele GL 1992 Intracellular signalling in the gonads. Endocrine Reviews 13 476-498.

Khan-Dawood FS, Huang JC \& Dawood MY 1989 Effect of human choroinic gonadotrophin and prostaglandin $\mathrm{F}_{2 \alpha}$ on progesterone production by human luteal cells. Journal of Steroid Biochemistry 33 941-947.

Marsh JM 1970 The stimulatory effect of luteinizing hormone on adenylate cyclase in the bovine corpus luteum. Journal of Biological Chemistry 245 1596-1603.

Marsh JM \& Savard K 1966 The stimulation of progesterone synthesis in bovine corpora lutea by cAMP. Steroids 8 133-148.

Morris JK \& Richards JS 1993 Hormone induction of luteinization and prostaglandin endoperoxide synthase-2 involves multiple cellular signalling pathways. Endocrinology 133 770-779.

Morris JK \& Richards JS 1995 Luteinizing hormone induces prostaglandin endoperoxide synthase-2 and luteinization in vitro by A-kinase and C-kinase pathways. Endocrinology 136 1549-1558.

Pallikaros Z, Schulster D, Baldwin SA, Helliwell RJ, Michael AE \& Cooke BA 1995 Characterization of site-directed antibodies to the LH receptor in functionally active gonadal cells and their differential effects on LH-stimulated signal transduction in Leydig tumour (MA-10) cells. Molecular and Cellular Endocrinology 14 $57-68$.

Peegel H, Randolph J Jr, Midgley R \& Menon KMJ 1994 In situ hybridisation of luteinizing hormone/human chorionic gonadotrophin receptor messenger ribonucleic acid during hormone-induced down-regulation and the subsequent recovery in rat corpus luteum. Endocrinology 135 1044-1051.

Polan ML, Seu D \& Tarlatzis B 1986 Human chorionic gonadotrophin stimulation of oestradiol production and androgen antagonism of gonadotrophin-stimulated responses in cultured human granulosa-luteal cells. Journal of Clinical Endocrinology and Metabolism 62 628-633.

Ratoosh SL \& Richards JS 1985 Regulation of the content and phosphorylation of RII by adenosine $3^{\prime}, 5^{\prime}$-monophosphate, follicle stimulating hormone, and estradiol in cultured granulosa cells. Endocrinology 117 917-927.

Richardson JM, Howard P, Massa JS \& Maurer RA 1990 Post-transcriptional regulation of cAMP-dependent protein kinase activity by cAMP in GH3 pituitary tumor cells. Evidence for increased degradation of catalytic subunit in the presence of cAMP. Journal of Biological Chemistry $26513635-13640$.

de Rooij J, Zwartkruis FJT, Verheijen MHG, Cool RH, Nijman SMB, Wittinghofer A \& Bos JL 1998 Epac is a Rap1 guanine-nucleotide-exchange factor directly activated by cAMP. Nature 396 474-477.

Segaloff DL, Wang H \& Richards JS 1990 Hormonal regulation of luteinizing hormone/chorionic gonadotrophin receptor mRNA in rat ovarian cells during follicular development and luteinization. Molecular Endocrinology 4 1856-1865.

Skalhegg BS \& Tasken K 2000 Specificity in the cAMP/PKA signalling pathway. Differential expression, regulation and subcellular localization of subunits of PKA. Frontiers in Bioscience $\mathbf{5}$ d678-d693. 
Spencer TE \& Bazer FW 2002 Biology of progesterone action during pregnancy recognition and maintenance of pregnancy. Frontiers in Bioscience 7 d1879-d1898.

Steinberg RA \& Agard DA 1981 Turnover of regulatory subunit of cyclic AMP-dependent protein kinase in S49 mouse lymphoma cells. Journal of Biological Chemistry 256 10731-10734.

Steiner AL, Ferrendelli JA \& Kipnis DM 1972 Radioimmunoassay for cyclic nucleotides. Effect of ischemia, changes during development and regional distribution of adenosine $3^{\prime}, 5^{\prime}$-monophosphate and guanosine $3^{\prime}, 5^{\prime}$-monophosphate in mouse brain. Journal of Biological Chemistry 274 1121-1124.

Strauss JF 3rd, Golos TG, Silavin SL, Soto EA \& Takagi K 1988 Involvement of cyclic AMP in the functions of granulosa and luteal cells: regulation of steroidogenesis. Progress in Clinical and Biological Research 267 177-200.

Strauss JF 3rd, Kallen CB, Christenson LK, Watari H, Devoto L, Arakane F, Kiriakidou M \& Sugawara T 1999 The steroidogenic acute regulatory protein (StAR): a window into the complexities of intracellular cholesterol trafficking. Recent Progress in Hormone Research 54 369-394.

Sugawara T, Holt JA, Driscoll D, Strauss JF 3rd, Lin D, Miller WL, Patterson D, Clancy KP, Hart IM, Clark BJ \& Stocco DM 1995 Human steroidogenic acute regulatory protein: functional activity in COS-1 cells, tissue-specific expression, and mapping of the structural gene to $8 \mathrm{p} 11.2$ and a pseudogene to chromosome 13 . PNAS 23 4778-4782.

Taylor SS, Buechler JA \& Yonemoto W 1990 cAMP-dependent protein kinase: framework for a diverse family of regulatory enzymes. Annual Review of Biochemistry 59 971-1005.
Webley GE, Luck MR \& Hearn JP 1988 Stimulation of cultured human granulosa cells with melatonin and catecholamines. Journal of Reproduction and Fertility 84 669-677.

Wheeler-Jones CPD, May MJ, Houliston RA \& Pearson JD 1996 Inhibition of MAP kinase kinase (MEK) blocks endothelial $\mathrm{PGI}_{2}$ release but has no effect on von Willebrand factor secretion or E-selectin expression. FEBS Letters 388 180-184.

Whitehouse BJ \& Abayasekara DR 1994 Roles of type I and type II isoenzymes of cyclic AMP-dependent protein kinase in steroidogenesis in rat adrenals. Journal of Molecular Endocrinology 12 192-202.

Wickings EJ, Hillier SG \& Reichert LE Jr 1986 Gonadotrophic control of steroidogenesis in human granulosa-lutein cells. Journal of Reproduction and Fertility 76 677-684.

Wood JR \& Strauss JF III 2002 Multiple signal transduction pathways regulate ovarian steroidogenesis. Reviews of Endocrine and Metabolic Disorders 3 33-46.

Zeleznik AJ 1998 In vivo responses of the primate corpus luteum to luteinizing hormone and chorionic gonadotrophin. PNAS 95 11002-11007.

Zeleznik AJ \& Somers JP 1999 Regulation of the primate corpus luteum: cellular and molecular perspectives. Trends in Endocrinology and Metabolism 5 189-193.

Received in final form 27 May 2004

Accepted 30 June 2004

Made available online as an

Accepted Preprint 13 July 2004 